\title{
EVALUATION OF MEMBRANE INTEGRITY OF FROZEN/THAWED DEER SPERMATOZOA: SHORT COMMUNICATION
}

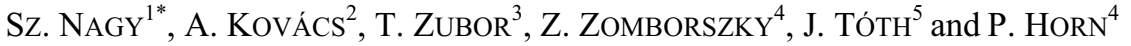 \\ ${ }^{1}$ Institute of Animal Breeding, Faculty of Agricultural Sciences, University of West \\ Hungary, H-9200 Mosonmagyaróvár, Vár 4, Hungary; ${ }^{2}$ Research Institute for Animal \\ Breeding and Nutrition, Herceghalom, Hungary; ${ }^{3}$ Embryo Ltd., Pécs, Hungary; ${ }^{4}$ Faculty \\ of Animal Sciences, University of Kaposvár, Kaposvár, Hungary; ${ }^{5}$ Pannon Equestrian \\ Academy and Specialist Secondary School for Agriculture, Kaposvár, Hungary
}

(Received August 27, 2000; accepted February 8, 2001)

\begin{abstract}
A simultaneous live/dead and acrosome staining, originally described for domestic mammals, was successfully applied on red deer (Cervus elaphus) and fallow deer (Dama dama) spermatozoa collected from the cauda epididymidis and vas deferens of shot stags. The staining is simple enough for routine application. Seven classes of spermatozoa were distinguished in the smears of frozen/thawed semen samples. Morphology, including cytoplasmic droplets, was evaluated as well. Percentage of live cells with intact acrosomes and with no other morphological aberrations might be a practical index of semen quality.
\end{abstract}

Key words: Deer, spermatozoa, membrane integrity, acrosome

Simultaneous information on the live/dead and acrosome status of spermatozoa is important for evaluation of the spermiogram and to find lesions after cryopreservation and other treatments. Garde et al. (1997) used a triple-stain technique to detect viability and acrosome status in deer spermatozoa.

A simple staining method was described for bull, boar and rabbit spermatozoa (Kovács and Foote, 1992), and later stain-permeable ('dead') sperm tails were also detected (Nagy et al., 1999). Based on the live/dead and acrosome status only, seven classes of spermatozoa can be distinguished; in addition, morphology - including cytoplasmic droplets - can also be evaluated.

After being successfully applied on different domestic mammals, this staining was tried out on deer spermatozoa.

Frozen semen of two Hungarian red deer (Cervus elaphus hippelaphus) and two fallow deer (Dama dama) stags, collected post mortem by massage from the cauda epididymidis and vas deferens (Zomborszky et al., 1999) was thawed, diluted $5 \times$ with $0.9 \% \mathrm{NaCl}$.

\footnotetext{
"Corresponding author; E-mail: szabio70@hotmail.com; Fax: +36 (96) 215-931
} 
The viability testing stain consists of $0.20 \%$ trypan blue (prepared from $0.4 \%$ trypan blue, Sigma T 8154 diluted $1: 1$ with $0.9 \% \mathrm{NaCl}$ ). This working solution is stable for several months at room temperature.

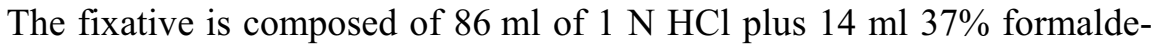
hyde solution and $0.2 \mathrm{~g}$ neutral red (Sigma N 2880). It is stable for about two months (until it has the smell of formaldehyde) at room temperature and may be used repeatedly.

The acrosome stain is 7.5\% Giemsa stock solution (Sigma GS 500) in distilled water prepared fresh before use.

\section{Staining procedure}

Equal drops of trypan blue and diluted semen were mixed on slides with the edge of another slide and smeared. Slides were air-dried near vertically at room temperature. After drying, they were fixed in a staining jar for $2 \mathrm{~min}$. They were rinsed with tap and distilled water, then stained in Giemsa for $3.5 \mathrm{~h}$ or overnight. Following rinsing in tap and distilled water, the slides were differentiated in distilled water for 2 min. After drying, they were mounted with Entellan (Merck, Darmstadt, Germany) or DPX (BDH, London, UK) and coverslipped.

Slides were evaluated using $40 \times$ dry, or $100 \times$ oil immersion objectives.

For live/dead assessment the posterior part of the head and the tail while on acrosome status the anterior part of the head provides information.

The posterior part of live sperm heads is white to light pink or light blue, that of dead sperm heads is black to dark violet. Live tails are pink, dead tails are dark. Intact acrosomes are purple, loose acrosomes are dark lavender, while damaged acrosomes are pale lavender.

The anterior part of the head of live spermatozoa with no acrosome is white to light pink, while that of the dead spermatozoa is white to pale grey. The postacrosomal ring is red.

Besides the live/dead and acrosome status, the whole morphology can be evaluated. Percentages of sperm cells with cytoplasmic droplets were also investigated: 200 cells per slide were counted and classified as normal, sperm cell with proximal or distal cytoplasmic droplet.

The following classes of spermatozoa were distinguished:

1. Live cell (head and tail), intact acrosome

2. Live head, dead tail, intact acrosome

3. Live cell, damaged/loose acrosome

4. Live cell, no acrosome

5. Dead cell, intact acrosome

6. Dead cell, damaged/loose acrosome

7. Dead cell, no acrosome

Different cells of the two species are shown in Figs 1 and 2. 


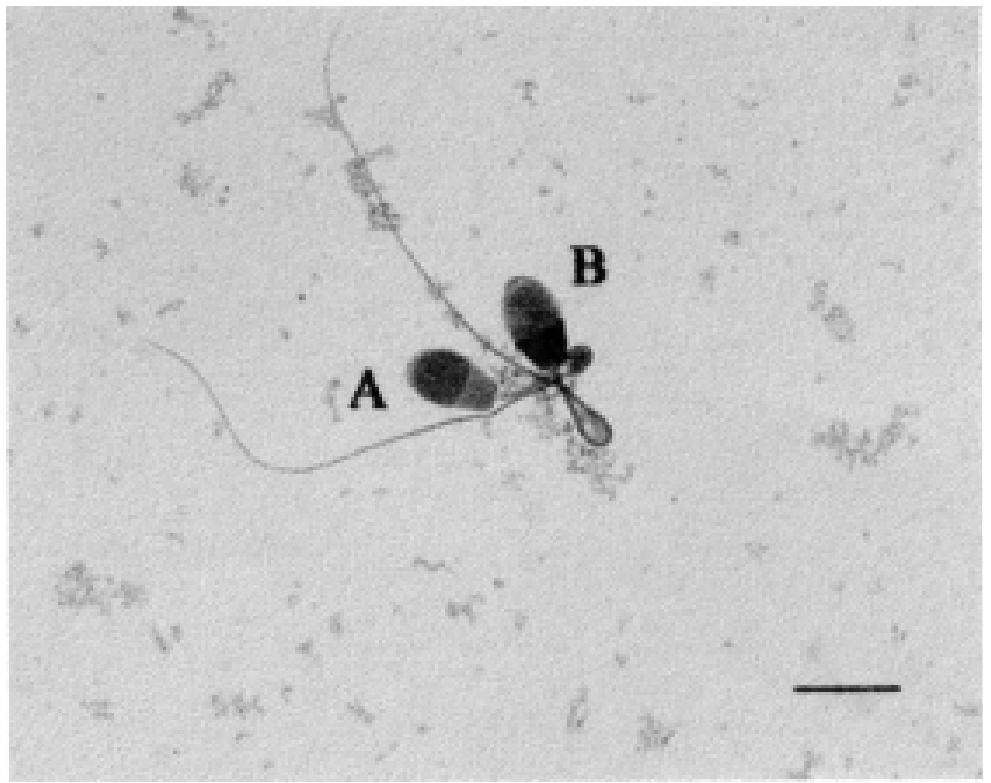

Fig. 1. Red deer spermatozoa. Bar shows $10 \mu \mathrm{m}$. A: 'Live' cell with intact acrosome and distal midpiece reflex defect (according to Barth and Oko, 1989). B: 'Dead' cell with damaged acrosome and bent tail

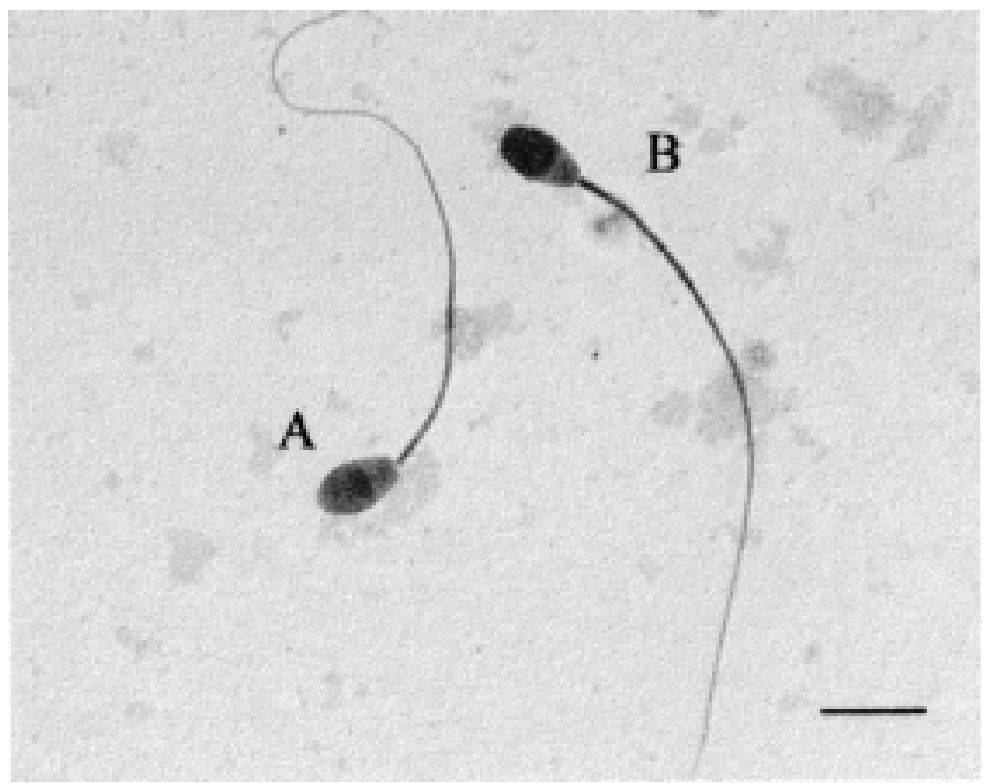

Fig. 2. Fallow deer spermatozoa. Bar shows $10 \mu \mathrm{m}$. A: 'Live' cell with intact acrosome and intact tail membrane. B: Sperm cell with intact head membrane and acrosome but with damaged tail membrane - this cell should be considered as 'dead' 
Percentages of spermatozoa of the seven classes are demonstrated in Table 1. Table 2 shows the proportion of spermatozoa with proximal or distal cytoplasmic droplets.

Table 1

Percentages of different classes of spermatozoa

\begin{tabular}{|c|c|c|c|c|}
\hline \multirow{2}{*}{ Classes } & \multicolumn{2}{|c|}{ Red deer } & \multicolumn{2}{|c|}{ Fallow deer } \\
\hline & Lábod 3 & Lábod 2 & Gyulaj 1 & Gyulaj 7 \\
\hline 1 & 18.5 & 40.5 & 36.0 & 39.0 \\
\hline 2 & 20.0 & 26.0 & 23.0 & 16.0 \\
\hline 3 & 7.5 & 0.5 & 5.5 & 1.0 \\
\hline 4 & 8.0 & 1.5 & 3.0 & 8.0 \\
\hline 5 & 0.5 & 0.0 & 0.5 & 0.0 \\
\hline 6 & 19.0 & 10.5 & 15.5 & 9.0 \\
\hline 7 & 26.5 & 21.0 & 16.5 & 27.0 \\
\hline Total & 100.0 & 100.0 & 100.0 & 100.0 \\
\hline
\end{tabular}

Table 2

Percentages of morphologically normal cells and spermatozoa with proximalor distal cytoplasmic droplets

\begin{tabular}{lrrrrr}
\hline \multirow{2}{*}{ Cell types } & \multicolumn{2}{c}{ Red deer } & & \multicolumn{2}{c}{ Fallow deer } \\
\cline { 2 - 3 } \cline { 5 - 5 } Normal & Lábod 3 & Lábod 2 & & Gyulaj 1 & Gyulaj 7 \\
\hline Proximal & 65.5 & 38.5 & & 68.0 & 57.0 \\
Distal & 0.5 & 0.5 & & 1.5 & 0.5 \\
\hline Total & 34.0 & 61.0 & & 30.5 & 42.5 \\
\hline
\end{tabular}

This method is simple enough for practical application and provides detailed information. Due to the dark stable precipitation created from trypan blue during fixation, dead cells are labelled stronger as compared to the triple staining (Garde et al., 1997).

The staining procedure may be interrupted after the first staining as well as after fixation and rinsing, which can be advantageous from the point of view of field research; furthermore, mounted smears can be stored and evaluated later.

Stained smears can be examined simply by a light microscope and seven cell types (based on membrane integrity) plus sperm morphology can be evaluated simultaneously.

The relatively high rate of sperm cells with distal cytoplasmic droplet can be explained by postmortem semen collection (Zomborszky et al., 1999). Distal 
droplets were present on $65-95 \%$ of the bovine spermatozoa stored in the cauda epididymis and they were shed immediately after mixing with seminal fluids (Barth and Oko, 1989), therefore we evaluated cells with distal droplets as normal in semen collected from the epididymis and vas deferens.

Percentage of 'live' (intact head, tail, and acrosome membrane) spermatozoa with no other morphological aberrations might be a practical index of semen quality.

\section{References}

Barth, A. D. and Oko, R. J. (1989): Abnormal morphology of bovine spermatozoa. Iowa Univ. Press, Ames, Iowa, USA. 285 pages.

Garde, J. J., Ortiz, N., García, A. and Gallego, L. (1997): Use of a triple-stain technique to detect viability and acrosome reaction in deer spermatozoa. Arch. Androl. 39, 1-9.

Kovács, A. and Foote, R. H. (1992): Viability and acrosome staining of bull, boar and rabbit spermatozoa. Biotech. Histochem. 67, 119-124.

Nagy, Sz., Házas, G., Bali Papp, Á., Iváncsics, J., Szász, F., Szász, F. Jr., Kovács, A. and Foote, R. H. (1999): Evaluation of sperm tail membrane integrity by light microscopy. Theriogenology 52, 1153-1159.

Zomborszky, Z., Zubor, T., Tóth, J. and Horn, P. (1999): Sperm collection from shot red deer stags (Cervus elaphus) and the utilisation of sperm frozen and subsequently thawed. Acta Vet. Hung. 47, 263-270. 